Article

\title{
Improvement of Corrosion Resistance and Electrical Conductivity of Stainless Steel 316L Bipolar Plate by Pickling and Passivation
}

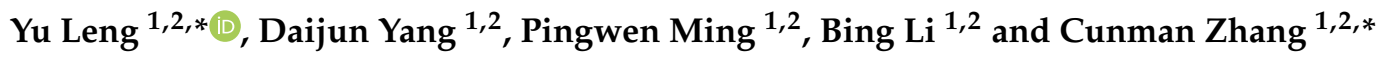 \\ 1 New Energy Automotive Engineering Centre, Tongji University, 4800 Caoangong Road, Shanghai 200029, China; \\ yangdaijun@tongji.edu.cn (D.Y.); pwming@tongji.edu.cn (P.M.); lb20016016@163.com (B.L.) \\ 2 School of Automotive Studies, Tongji University, 4800 Caoangong Road, Shanghai 200029, China \\ * Correspondence: lengyu@tongji.edu.cn (Y.L.); zhangcunman@tongji.edu.cn (C.Z.)
}

Citation: Leng, Y.; Yang, D.; Ming, P.; Li, B.; Zhang, C. Improvement of Corrosion Resistance and Electrical Conductivity of Stainless Steel 316L Bipolar Plate by Pickling and Passivation. World Electr. Veh. J. 2021, 12, 101. https://doi.org/10.3390/ wevj12030101

Academic Editor: Michael Fowler

Received: 10 July 2021

Accepted: 27 July 2021

Published: 28 July 2021

Publisher's Note: MDPI stays neutral with regard to jurisdictional claims in published maps and institutional affiliations.

Copyright: (c) 2021 by the authors. Licensee MDPI, Basel, Switzerland. This article is an open access article distributed under the terms and conditions of the Creative Commons Attribution (CC BY) license (https:// creativecommons.org/licenses/by/ $4.0 /)$.

\begin{abstract}
Corrosion resistance and electrical conductivity of stainless steel bipolar plate remains a big challenge while it has been regarded as the most promising candidate for proton exchange membrane fuel cell. The purpose of this paper is to study the effects of pickling and passivation by sulfuric acid and a mixture of nitric and fluoric acids, respectively, on corrosion resistance and electrical conductivity of stainless steel 316L (SS316L) bipolar plate. First, pickling of the specimens of SS316L is performed in a $15 \mathrm{wt} . \% \mathrm{H}_{2} \mathrm{SO}_{4}$. Afterwards, the specimens are passivated in a mixture of $12 \mathrm{wt} . \%$ $\mathrm{HF}$ and $4 \mathrm{wt} . \% \mathrm{HNO}_{3}$. Electrochemical and interfacial conductivity tests are conducted to examine the change in corrosion resistance and electrical conductivity of SS316L. Finally, scanning electron microscopy (SEM), X-ray photoelectron spectroscopy (XPS) and atomic force microscopy (AFM) reveal the evolution of surface morphology, chemical composition and surface conductivity. The results show that the corrosion resistance and electrical conductivity of SS316L could be improved significantly by pickling and passivation. The increase in Cr:Fe ratio as well as a more uniform surface with higher conductivity is the main reason for the improvement of corrosion resistance and interfacial conductivity of SS316L.
\end{abstract}

Keywords: proton exchange membrane fuel cell; stainless steel bipolar plate; pickling and passivation; corrosion resistance; electrical conductivity

\section{Introduction}

The proton exchange membrane fuel cell (PEMFC) has been considered to be a promising energy conservation device due to its high efficiency, high power density, low operating temperature, low noise, quick start-up and zero pollutions [1]. As a key component in PEMFC, bipolar plates account for 20-30 and 60-80\% of the cost and weight, respectively [2]. Due to the multifunctional characteristics of bipolar plates, the property requirements of the materials are stringent. Among the materials investigated for bipolar plates, stainless steel (SS) is regarded as one of the most promising candidates for PEMFC, especially in automotive applications because of its high electrical and thermal conductivity, low gas permeability, high strength and toughness, superior formability and relatively low cost [3]. Moreover, a light weight of PEMFC can be achieved by utilizing ultrathin stainless steel bipolar plate with a thickness of $0.1 \mathrm{~mm}$ or even thinner. However, corrosion of stainless steel bipolar plate remains a big challenge [4]. Forming of metal oxides with low conductivity and dissolution of metal ions, both of which impair the performance and durability of PEMFC remarkably, would emerge during the process of corrosion. In addition, the interfacial contact resistance (ICR) of stainless steel base material is much higher than that of the 2020 DOE Targets [5]. Therefore, the improvement of corrosion resistance and electrical conductivity of stainless steel bipolar plate is of great significance for PEMFC with higher performance and longer durability. 
Adding coatings, such as metal nitrides, metal carbon or amorphous carbon through physical vapor deposition (PVD) methods is the most commonly used way to improve the corrosion resistance and interfacial conductivity of stainless steel bipolar plates at present [6]. However, the cost of bipolar plates will be increased with reduced productivity. In addition, defects such as pinholes and microcracks that may appear in the coatings would become the place where corrosion initiates. The corrosion rate of bare stainless steels at the defects of coatings may also be accelerated because of higher anode corrosion current density. Therefore, some researchers attempted to improve the corrosion resistance of bare stainless steels by novel alloy design and surface modification. M.P. Brady et al. [7] developed a Fe-Cr-V ferritic stainless steel alloy and studied the effects of pre-oxidation and nitridation. The results indicate that pre-oxidation and nitridation are effective in improving corrosion resistance and reducing ICR of the Fe-Cr-V alloy. D. M. Zhang et al. [8] investigated the effects of chemical, heat and electrochemical treatments on corrosion and ICR of a novel Fe-Ni-Cr alloy. Corrosion current density and ICR of the Fe-Ni-Cr alloy with the surface modification method mentioned in their work can be reduced to $0.0462 \mu \mathrm{A} \cdot \mathrm{cm}^{-2}\left(0.5 \mathrm{M} \mathrm{H}_{2} \mathrm{SO}_{4}+2 \mathrm{ppm} \mathrm{HF}\right)$ and $12.4 \mathrm{~m} \Omega \cdot \mathrm{cm}^{2}$ (at $\left.140 \mathrm{~N} \cdot \mathrm{cm}^{-2}\right)$, respectively. K. M. Kim et al. [9] studied the effects of $\mathrm{HCl}$ and $\mathrm{NaOH}$ solutions on the ICR of SS446M. Their results reveal that the ICR of SS446M treated by $\mathrm{HCl}$ solutions can be reduced significantly. O. Ishigami et al. [10] introduced a method for passivating stainless steel by $\mathrm{NaOH}$ solutions with $\mathrm{pH}$ and temperature in the range of 9-12 and 40-60 ${ }^{\circ} \mathrm{C}$, respectively. In the patent by Y. T. Jeon et al. [11], a surface modification method to improve the corrosion resistance and interfacial conductivity by dipping stainless steel into a mixed solution of $\mathrm{HNO}_{3}$ and $\mathrm{H}_{2} \mathrm{SO}_{4}$ was described. T. Ishii et al. [12] proposed a novel ferritic stainless steel alloy and the corresponding surface passivating method. An aqueous mixture of $\mathrm{HF}$ and $\mathrm{HNO}_{3}$ with the ratio of $\mathrm{HF}: \mathrm{HNO}_{3}$ larger than 2.5 was used to enhance corrosion resistance and conductivity of the aforementioned ferritic stainless steel. J. Kim et al. [13] also developed a novel ferritic stainless steel with excellent corrosion resistance and a low ICR value. The ferritic stainless steel named Poss470FC was treated first in a solution of $10-20 \mathrm{wt} . \% \mathrm{H}_{2} \mathrm{SO}_{4}$ at a temperature of $50-75{ }^{\circ} \mathrm{C}$ and then in a mixture of $1-10 \mathrm{wt} . \%$ $\mathrm{HF}$ and $10-20$ wt. $\% \mathrm{HNO}_{3}$ at a temperature of $40-60{ }^{\circ} \mathrm{C}$. Corrosion current density and ICR of Poss470FC could be reduced to below $0.1 \mu \mathrm{A} \cdot \mathrm{cm}^{-2}\left(1 \mathrm{M} \mathrm{H}_{2} \mathrm{SO}_{4}+2 \mathrm{ppm} \mathrm{HF}\right)$ and $5 \mathrm{~m} \Omega \cdot \mathrm{cm}^{2}$ (at $140 \mathrm{~N} \cdot \mathrm{cm}^{-2}$ ), respectively. The excellent corrosion resistance and conductivity of Poss470FC after treatment was attributed to higher ratios of $\mathrm{Cr} / \mathrm{Fe}$ oxides and $\mathrm{Cr}(\mathrm{OH})_{3} / \mathrm{Cr}$ oxide in a few nanometers of the surface of the stainless steel. Although pickling and passivation has been used to improve the corrosion resistance and electrical conductivity of stainless steel in the aforementioned studies, most of them are focused on ferritic stainless steel. The effects of pickling and passivation on corrosion resistance and electrical conductivity of austenitic stainless steel remain unclear.

This paper aims to investigate the effects and reveal the mechanisms of pickling and passivation with sulfuric acid and a mixture of nitric and fluoric acids, respectively, on corrosion resistance and interfacial electrical conductivity of austenitic stainless steel SS316L. First, pickling of the specimens of SS316L was performed in a $15 \mathrm{wt} . \% \mathrm{H}_{2} \mathrm{SO}_{4}$ at $60{ }^{\circ} \mathrm{C}$ for $90 \mathrm{~s}$. Afterwards, the specimens were passivated in a mixture of $12 \mathrm{wt} . \% \mathrm{HF}$ and 4 wt. $\% \mathrm{HNO}_{3}$ at $60{ }^{\circ} \mathrm{C}$ for $150 \mathrm{~s}$. Then electrochemical tests were conducted in solutions with $0.5 \mathrm{M} \mathrm{H}_{2} \mathrm{SO}_{4}$ and $2 \mathrm{ppm} \mathrm{HF}$ to investigate the variation of SS316L after pickling and passivation. The ICR of the pickling and passivation treated specimens under different compression pressures were also examined. Finally, scanning electron microscopy (SEM), $X$-ray photoelectron spectroscopy (XPS) and atomic force microscopy (AFM) revealed the evolution of the surface morphology, chemical composition and surface conductivity of SS316L under pickling and passivation treatment. 


\section{Materials and Methods}

\subsection{Material and Surface Modification}

The stainless steel used in the present was cold rolled and bright annealing-treated SS316L foil with a thickness of $0.1 \mathrm{~mm}$. The specimens were cut into a size of about $20 \mathrm{~mm} \times 30 \mathrm{~mm}$ with wire cutting electro discharge machining. All of the specimens were cleaned with ethanol and deionized water sequentially at room temperature for $5 \mathrm{~min}$ in an ultrasonic machine with a frequency of $40 \mathrm{kHz}$ (PS-D40). After they were dried in the air, the specimens were pickling and passivation treated. Based on the work by J. Kim et al. [13], the original passive film on stainless steel needed to be removed in a $10-20 \mathrm{wt} . \% \mathrm{H}_{2} \mathrm{SO}_{4}$ before passivation treatment. In addition, the mass ratio of $\mathrm{HF}: \mathrm{HNO}_{3}$ for passivation treatment needed to be larger than 2.5 in order to achieve an ICR of $10 \mathrm{~m} \Omega \cdot \mathrm{cm}^{2}$ or less for the ferritic stainless steel invented according to the work by T. Ishii et al. [12]. However, a higher concentration of hydrofluoric acid would be harmful to both the human body and the environment, while too low a concentration of hydrofluoric acid might lead to longer time of passivation. Therefore, a solution of $15 \mathrm{wt} . \% \mathrm{H}_{2} \mathrm{SO}_{4}$ and a mixture of $12 \mathrm{wt} . \%$ $\mathrm{HF}$ and $4 \mathrm{wt} . \% \mathrm{HNO}_{3}$ were utilized in the present paper for pickling and passivation treatment of SS316L, respectively. In the meanwhile, J. Kim et al. [13] also indicated that the appropriate temperatures for pickling and passivation treatment might be in the range of $50-75^{\circ} \mathrm{C}$ and $40-60{ }^{\circ} \mathrm{C}$, respectively, while the appropriate processing times (t) for pickling and passivation treatment could be calculated by Formulas (1) and (2), respectively. The surface roughness of SS316L used in the present was tested to be approximately $0.3 \mu \mathrm{m}$. Consequently, the time for pickling and passivation treatment was determined to be 90 and $150 \mathrm{~s}$, respectively. Moreover, the temperatures utilized for pickling and passivation treatment were both $60{ }^{\circ} \mathrm{C}$.

$$
\begin{aligned}
& 99-3.18(1 / \mathrm{Ra}) \leq \mathrm{t}(\text { second }) \leq 153-3.18(1 / \mathrm{Ra}) \\
& 120+6.73(1 / \mathrm{Ra}) \leq \mathrm{t}(\text { second }) \leq 140+6.73(1 / \mathrm{Ra})
\end{aligned}
$$

where $\mathrm{Ra}$ is the surface roughness of the treated stainless steel.

\subsection{Electrochemical and ICR Tests}

The electrochemical tests were carried out in a corrosion pool with an exposure area of $1.25 \mathrm{~cm}^{2}$. A three-electrode electrochemical workstation (CHI660E) was utilized for all electrochemical tests. In the three-electrode system, the specimens were served as the working electrode while saturated $\mathrm{Ag} / \mathrm{AgCl}$ and platinum mesh were used as the reference and counter electrodes, respectively. The solutions utilized for electrochemical tests were $0.5 \mathrm{M} \mathrm{H}_{2} \mathrm{SO}_{4}$ and $2 \mathrm{ppm}$ HF. All the specimens were stabilized at the open circuit potential (OCP) for $1 \mathrm{~h}$ before potentiodynamic and potentiostatic tests. For potentiodynamic tests, the potential varied from -0.6 to $1.3 \mathrm{~V}$ (vs. $\mathrm{Ag} / \mathrm{AgCl}$ ) with a scanning rate of $1 \mathrm{mV} \cdot \mathrm{s}^{-1}$. In the meanwhile, argon was bubbled in the solutions for potentiodynamic tests. Potentiostatic tests were conducted at the potential of $0.6 \mathrm{~V}$ (vs. $\mathrm{Ag} / \mathrm{AgCl}$ ) with oxygen bubbles for $30 \mathrm{~min}$. The temperatures for all electrochemical tests were set to be $70{ }^{\circ} \mathrm{C}$. The method utilized for measuring ICR between the specimens and gas diffusion layer could be found in the work by G. Yang et al. [14]. The TGP-H-060 type carbon paper produced by Toray Industries Inc was used as the gas diffusion layer for ICR testing. The compression pressure in a PEMFC is normally in the range of 0.1 to $1.5 \mathrm{MPa}$ while the compression pressure utilized for comparing ICR of materials for bipolar plate are always in the range of 1.4 to 2.0 MPa [1]. In addition, a smaller interval of compression pressure during ICR testing may contribute to smooth curves. Therefore, the compacting force was loaded gradually from 0.1 to $2.0 \mathrm{MPa}$ with an interval of $0.1 \mathrm{MPa}$.

\subsection{Microstructure Characterization}

SEM observations were conducted to reveal the surface morphology of the specimens by using an environment scanning electron microscope (Quanta FEG 250). An accelerating voltage of $20 \mathrm{kV}$ was used for SEM characterization. The contents of $\mathrm{Fe}, \mathrm{Cr}$ and $\mathrm{O}$ elements 
in the surface of specimens were analyzed by XPS (ESCALAB 250Xi) with an Auger electron spectroscopy (AES). Five etch levels were chosen for studying the depth profiles of $\mathrm{Fe}, \mathrm{Cr}$ and $\mathrm{O}$ elements by etching the surface with argon ions. The etching rate of all the specimens was $0.29 \mathrm{~nm} \cdot \mathrm{s}^{-1}$. In the meanwhile, the surface roughness and electrical properties of the specimens were studied by AFM (Dimension Icon).

\section{Results and Discussions}

\subsection{Electrochemical Tests}

The corrosion resistance of the pickling and passivation treated SS316L in anodic and cathodic environment of PEMFC was tested by potentiodynamic and potentiostatic tests, respectively. The results are shown in Figure 1. It can be seen that the corrosion potential ( $\left.\mathrm{E}_{\text {corr. }}\right)$ and corrosion current density $\left(\mathrm{I}_{\text {corr. }}\right)$ of pickling and passivation treated SS316L was close to that of the original SS316L (Figure 1a). However, the current density of the treated SS316L in the potential range of -0.2 to $0 \mathrm{~V}$ (vs. $\mathrm{Ag} / \mathrm{AgCl}$ ), which is the typical anode potential range of PEMFC [15], was lower than that of original SS316L. From the results of potentiostatic tests (Figure 1b), it can be concluded that the current density of treated SS316L at the potential of $0.6 \mathrm{~V}$ for $0.5 \mathrm{~h}$ is $1.84 \mu \mathrm{A} \cdot \mathrm{cm}^{-2}$. The current density of the treated SS316L was approximately one order of magnitude lower than the original SS316L in the simulated cathodic environment of PEMFC. The results indicate that the corrosion resistance of SS316L can be improved by pickling and passivation method described in the present paper. Moreover, two anodic current peaks were observed in the Tafel curve of the treated SS316L. According to the work by S. Rajasekar et al. [15] and M. Abdallah [16], the first anodic peak was caused by the formation of Fe, $\mathrm{Cr}$ and $\mathrm{Ni}$ oxides, while the second anodic peak was attributed to oxides in a higher valence state. For the original SS316L, the oxides of $\mathrm{Fe}, \mathrm{Cr}$ and $\mathrm{Ni}$ may have tended to be in a higher valence state due to higher oxygen content in the surface. However, the oxides in a higher valence state might have been removed during the process of pickling and passivation treatment for the treated SS316L. Therefore, two anodic current peaks appear in the Tafel curve of the treated SS316L.
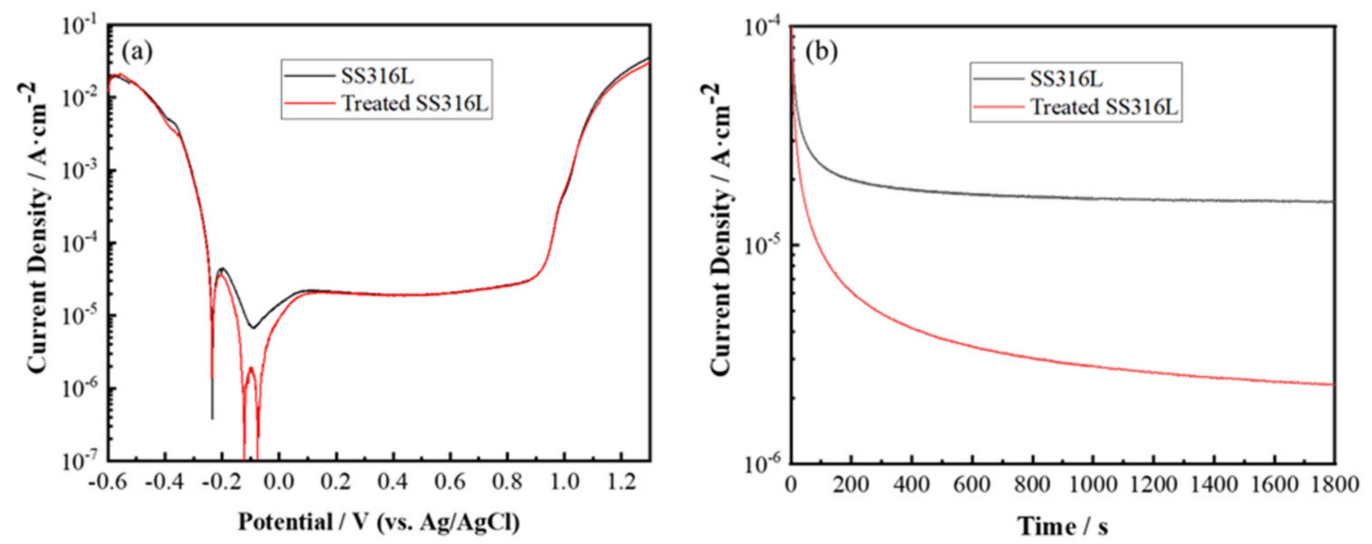

Figure 1. Electrochemical tests for original and treated stainless steel 316L (SS316L). (a) potentiodynamic tests in $0.5 \mathrm{M} \mathrm{H}_{2} \mathrm{SO}_{4}$ and $2 \mathrm{ppm}$ HF solutions bubbled with argon at $70{ }^{\circ} \mathrm{C}$ and (b) potentiostatic tests in $0.5 \mathrm{M} \mathrm{H}_{2} \mathrm{SO}_{4}$ and 2 ppm HF solutions bubbled with oxygen at $70{ }^{\circ} \mathrm{C}$ for $0.5 \mathrm{~h}$.

\subsection{ICR Tests}

The ICR of the original and treated SS316L at different compression pressure was also investigated, as shown in Figure 2. The ICR of the original SS316L before potentiodynamic tests at the compression pressure of $140 \mathrm{~N} \cdot \mathrm{cm}^{-2}$ is $286.7 \mathrm{~m} \Omega \cdot \mathrm{cm}^{2}$ (Figure 2a). On the contrary, ICR of the treated SS316L before the potentiodynamic tests would decrease to $11.3 \mathrm{~m} \Omega \cdot \mathrm{cm}^{2}$ at the compression pressure of $140 \mathrm{~N} \cdot \mathrm{cm}^{-2}$ (Figure 2a), which is approaching the $2020 \mathrm{DOE}$ target of $10 \mathrm{~m} \Omega \cdot \mathrm{cm}^{2}$ at the compression pressure of $140 \mathrm{~N} \cdot \mathrm{cm}^{-2}$. The results show that the interfacial conductivity of SS316L can be improved significantly when it is treated by pickling and passivation method in the present paper. The ICR 
of the original and treated SS316L after potentiodynamic tests are also investigated. As can be seen from Figure 2b, the ICR of the treated SS316L after potentiodynamic test was $29.5 \mathrm{~m} \Omega \cdot \mathrm{cm}^{2}$ at the compression pressure of $140 \mathrm{~N} \cdot \mathrm{cm}^{-2}$ while that of the original SS316L after potentiodynamic testing was $38.6 \mathrm{~m} \Omega \cdot \mathrm{cm}^{2}$ at the compression pressure of $140 \mathrm{~N} \cdot \mathrm{cm}^{-2}$. The results indicate that ICR of the treated SS316L would increase slightly after potentiodynamic testing in $0.5 \mathrm{M} \mathrm{H}_{2} \mathrm{SO}_{4}$ and $2 \mathrm{ppm} \mathrm{HF}$ bubbled with argon. This may probably have been caused by transpassivation of the treated SS316L at higher potentials during potentiodynamic tests. It can also be seen that the ICR of original SS316L would decrease significantly and be close to that of treated SS316L after potentiodynamic test. The reason for this phenomenon may be that primary oxides, especially the iron oxides in the surface of original SS316L are removed during potentiodynamic test. This will be discussed in detail in the following sections.
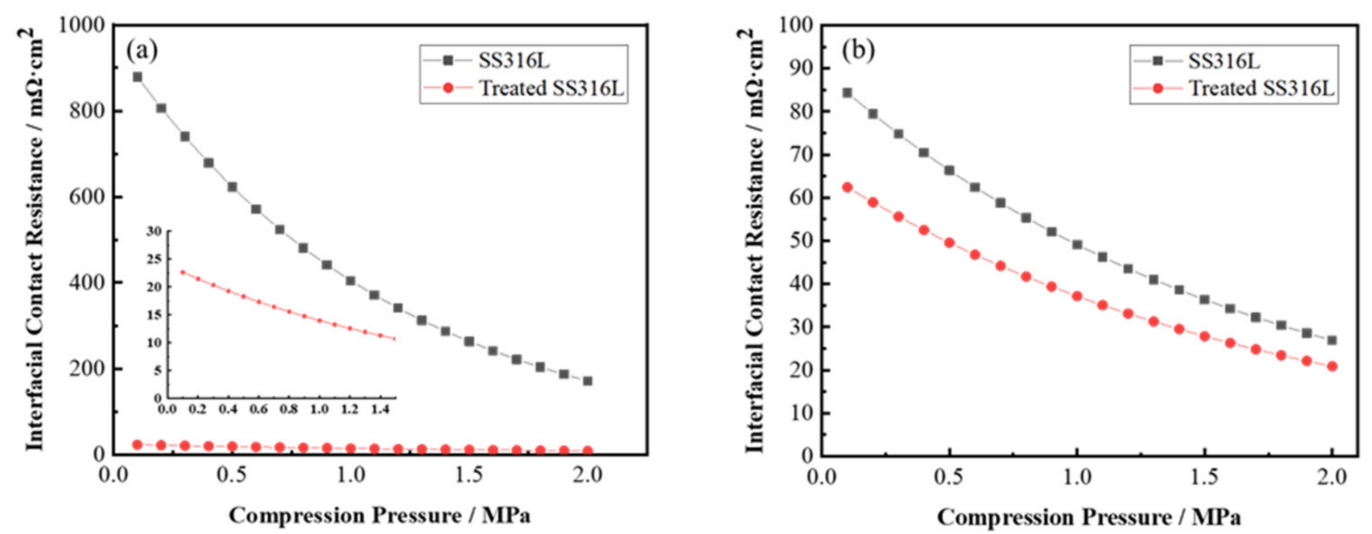

Figure 2. Interfacial contact resistance (ICR) of original and treated SS316L. (a) before potentiodynamic tests and (b) after potentiodynamic tests.

\subsection{SEM Characterization}

In order to reveal the mechanism of evolution of corrosion resistance and interfacial conductivity for SS316L under pickling and passivation treatment and potentiodynamic tests, the surface morphology of SS316L before and after potentiodynamic tests is characterized by SEM. The results are shown in Figure 3. As compared to original SS316L (Figure 3a), the surface of pickling and passivation treated SS316L (Figure 3c) became rougher with many little bulges within a few micrometers. In the meanwhile, the surface of SS316L became more uniform when compared to the original rolled surface of SS316L. The variation of surface morphology may contribute to higher interfacial conductivity for the treated SS316L. In the meanwhile, the surface morphology of the original and treated SS316L after potentiodynamic tests were also studied (Figure 3b,d). According to the results of SEM, pitting and especially intergranular corrosion would appear during potentiodynamic tests for both the original and treated SS316L. It can be concluded that the corrosion mechanism and evolution of surface morphology for both original and treated SS316L during potentiodynamic tests were identical. Therefore, the ICR of the original SS316L became close to that of treated SS316L.

\subsection{AFM Characterization}

In addition to surface morphology characterization, the surface roughness and electrical conductivity of SS316L were investigated by AFM for further study of the effects of pickling and passivation as well as potentiodynamic tests on SS316L, as shown in Figure 4. It can be seen that the surface seemed to be more uniform for the treated SS316L (Figure 4c) although it had a larger surface roughness when compared to the original SS316L (Figure 4a). In addition, the surface roughness would become larger for both the original and treated SS316L after potentiodynamic tests (Figure 4b,d). Moreover, the treated SS316L after potentiodynamic tests tended to have the largest surface roughness. In the 
meanwhile, the electrical properties of the original and treated SS316L with and without potentiodynamic tests were analyzed by applying a potential of $0.8 \mathrm{~V}$ on them. The results are shown in Figure 5. From the current plots by AFM, it can be seen that the electrical conductivity of treated SS316L was better than the original one, either before or after potentiodynamic tests. This is in accordance with the results of ICR tests. The current plots also reveal that the regions with high conductivity are dispersed fine particles for both original and treated SS316L before potentiodynamic tests. For the specimens after potentiodynamic tests, the regions along the grain boundary tended to be more conductive. This may have been caused by reducing less conductive alloy oxides, such as iron oxides, and increasing more conductive alloy compounds, such as oxides and hydroxides of chromium. In addition, the treated SS316L after potentiodynamic test (Figure 5d) seemed to be more conductive than the one before potentiodynamic test according to the results of AFM. The result is contrary to ICR tests of the treated SS316L before and after potentiodynamic tests. One possible reason for this phenomenon is the reduced contact area between the treated SS316L and carbon paper TGP-H-060 after potentiodynamic tests. The groove along the grain boundary and surface roughness would become larger as intergranular corrosion emerged during the process of the potentiodynamic tests. Therefore, the real contact area between the treated SS316L and carbon paper became smaller. As a result, the ICR of the treated SS316L after potentiodynamic test increased when compared to the one before potentiodynamic test even though the surface conductivity of the treated SS316L after potentiodynamic tests increased.
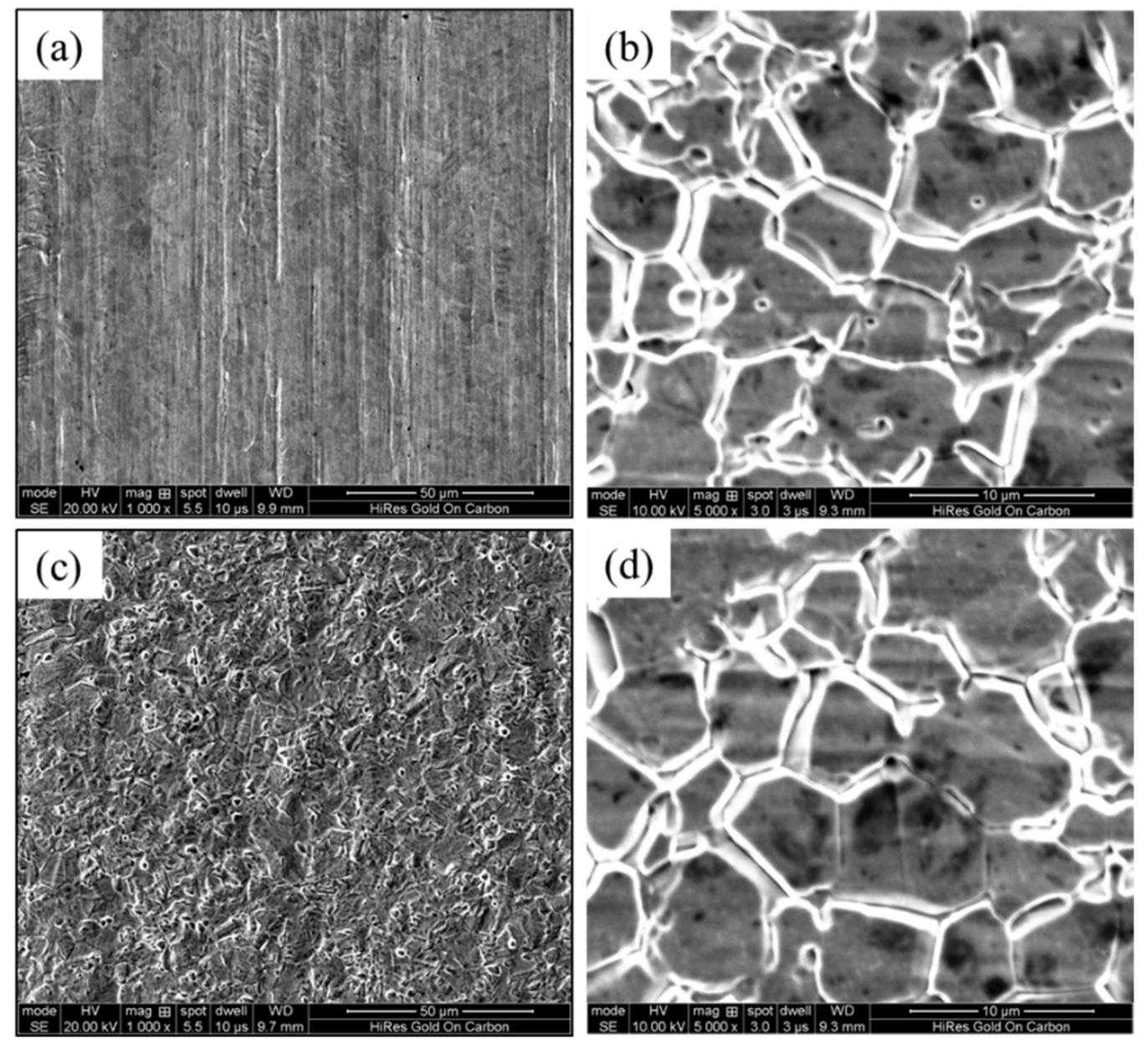

Figure 3. Surface morphology of original and treated SS316L by scanning electron microscopy (SEM). (a) original SS316L before potentiodynamic tests; (b) original SS316L after potentiodynamic tests; (c) treated SS316L before potentiodynamic tests and (d) treated SS316L after potentiodynamic tests. 

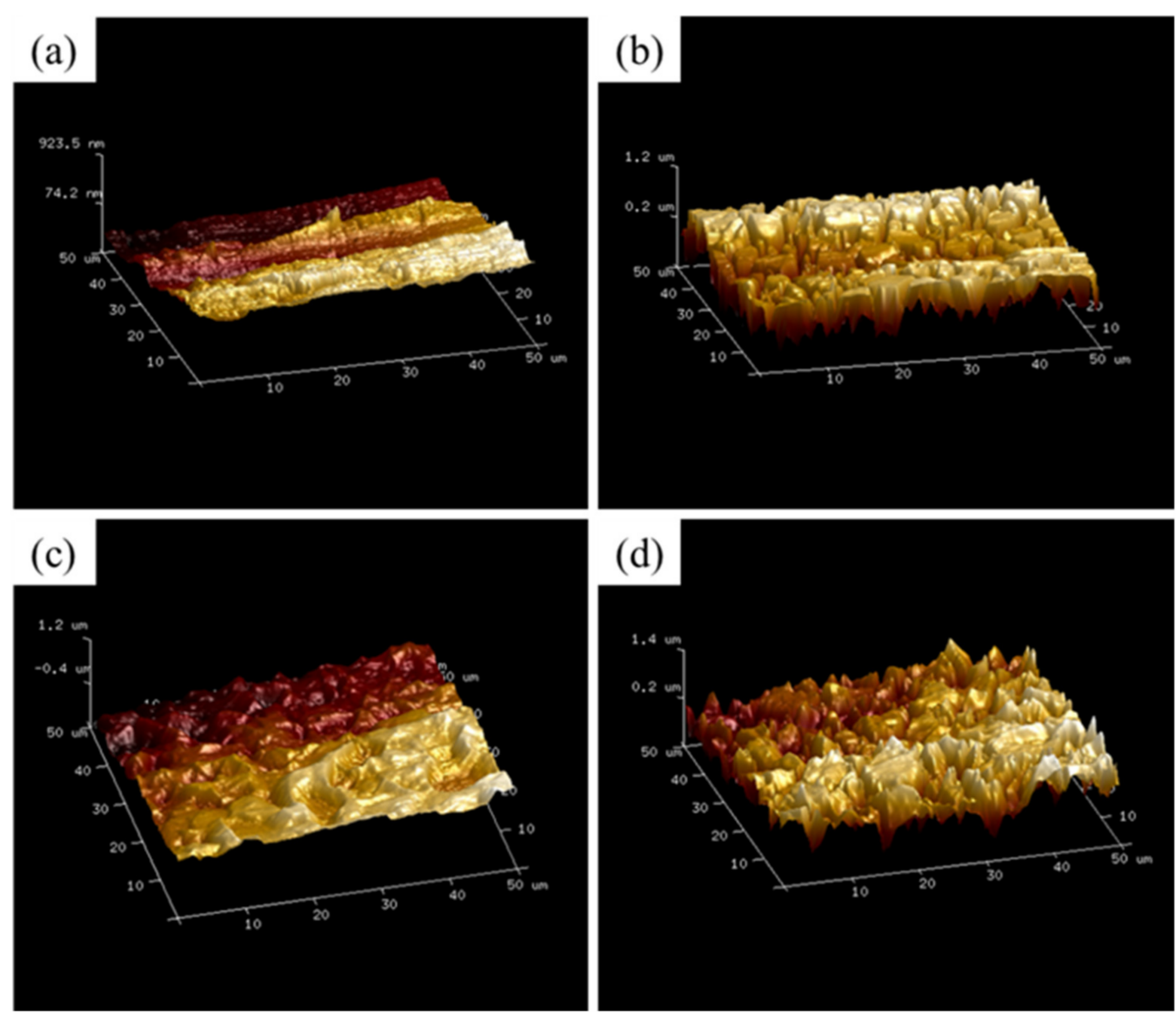

Figure 4. Surface roughness of original and treated SS316L by atomic force microscopy (AFM). (a) original SS316L before potentiodynamic tests; (b) original SS316L after potentiodynamic tests; (c) treated SS316L before potentiodynamic tests and (d) treated SS316L after potentiodynamic tests.

\subsection{XPS Characterization}

The depth profiles of Fe, $\mathrm{Cr}$ and $\mathrm{O}$ in the surface of treated SS316L were analyzed by XPS, of which the results are shown in Figure 6. The oxygen content in the surface of original SS316L tended to be higher than the treated SS316L. Besides, the ratio of Cr:Fe in the surface of original SS316L was much lower compared to the pickling and passivation treated one. On the contrary, the oxygen ratio became relatively low and the ratio of $\mathrm{Cr}$ :Fe increased to be larger than one within the depth of approximately $3 \mathrm{~nm}$ for treated SS316L. The results indicate that iron or iron oxides may be removed while the more corrosion resistant and conductive chromium, chromium oxides or hydroxides and chromium carbides are kept in the surface of SS316L by pickling and passivation treatment. Therefore, the corrosion resistance and interfacial conductivity of SS316L can be improved significantly. The results of XPS are in accordance with those of the electrochemical and ICR tests, SEM and AFM characterizations. For the treated SS316L (Figure 6c), the oxygen content in the surface will increase slightly after potentiodynamic tests. In the meanwhile, the ratio of $\mathrm{Cr}$ :Fe would decrease to smaller than 0.5. However, the ratio of $\mathrm{Cr}$ :Fe is still larger than that in the surface of original SS316L. The results of XPS also show that the passive film with higher corrosion resistance and conductivity formed in the surface of pickling and passivation treated SS316L may be unstable in the solution of $0.5 \mathrm{M} \mathrm{H}_{2} \mathrm{SO}_{4}$ and $2 \mathrm{ppm} \mathrm{HF}$, especially at the potentials higher than $0.9 \mathrm{~V}$ (vs. $\mathrm{Ag} / \mathrm{AgCl}$ ). 

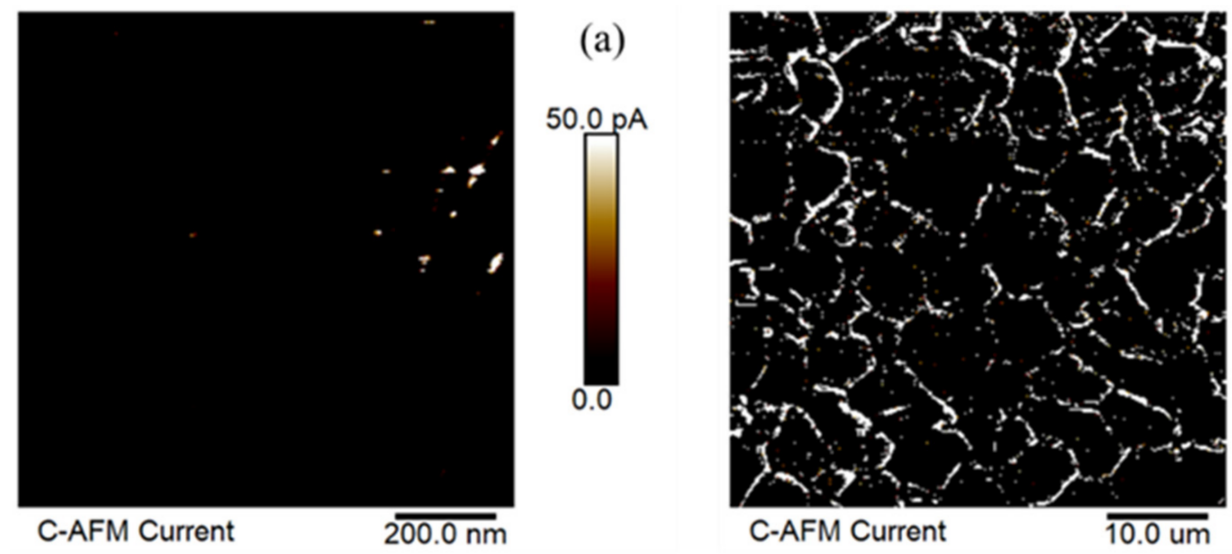

(b)

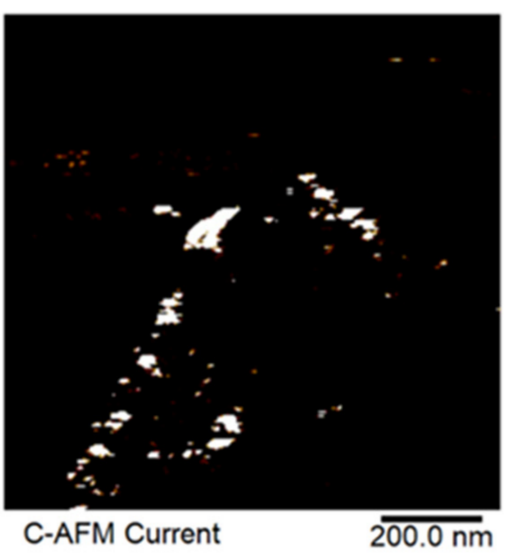

(c)

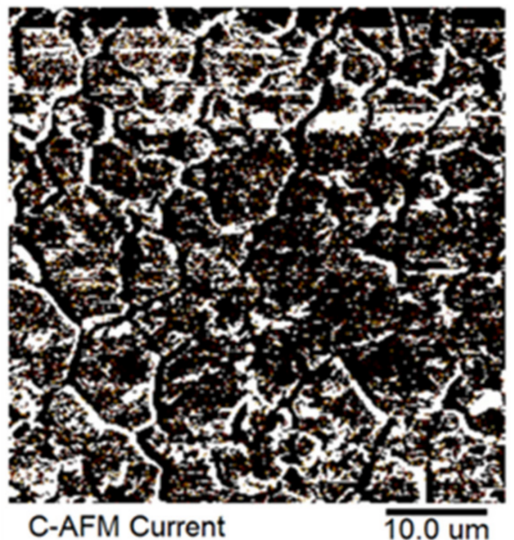

(d)
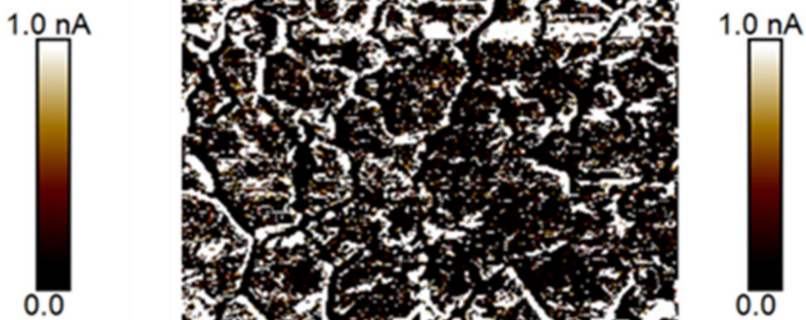

Figure 5. Conductivity of original and treated SS316L by AFM. (a) original SS316L before potentiodynamic tests; (b) original SS316L after potentiodynamic tests; (c) treated SS316L before potentiodynamic tests and (d) treated SS316L after potentiodynamic tests.
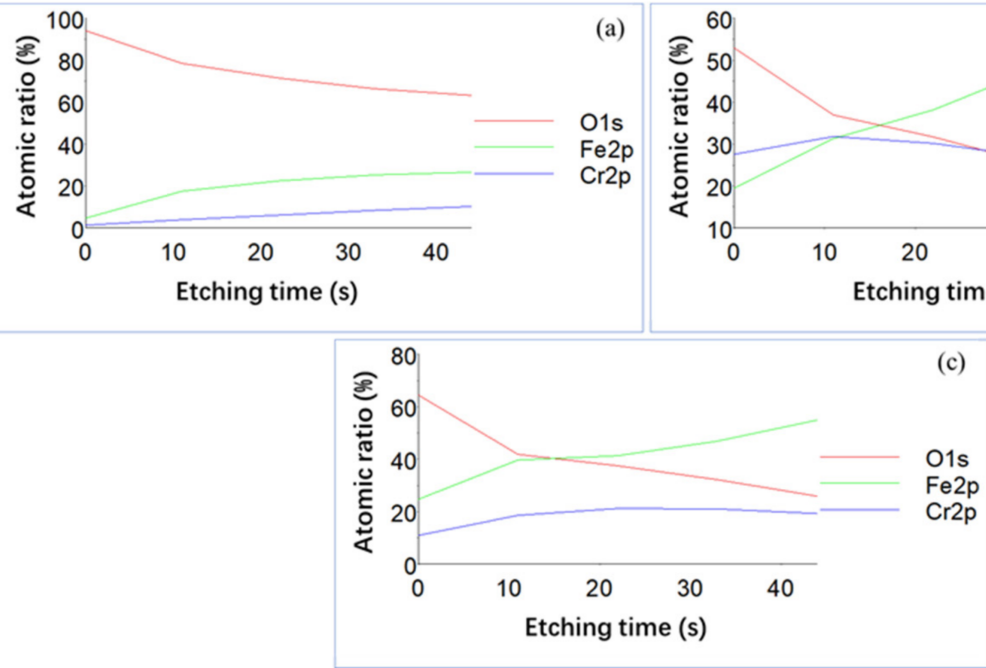

(b)

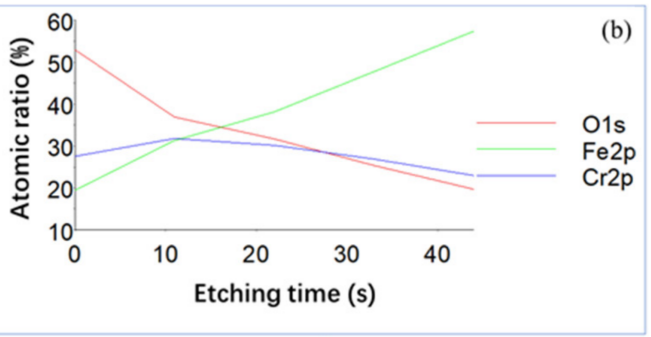

(c) $1 \mathrm{~s}$ rep

Figure 6. Depth profiles of Fe, $\mathrm{Cr}$ and O elements in the surface of original and treated SS316L by X-ray photoelectron spectroscopy (XPS). (a) original SS316L before potentiodynamic tests; (b) treated SS316L before potentiodynamic tests and (c) treated SS316L after potentiodynamic tests.

\section{Conclusions}

The austenitic stainless steel SS316L has been pickling and passivation treated by sulfuric acid and a mixture of nitric and fluoric acids, respectively. The effects of pickling and passivation on corrosion resistance and interfacial conductivity of SS316L were investigated by electrochemical and ICR tests. In the meanwhile, the evolution of surface morphology, 
roughness, interfacial conductivity and chemical composition were characterized by SEM, AFM and XPS. The main conclusions are as follows.

1. The corrosion resistance of the pickling and passivation treated SS316L can be increased in both simulated anodic and cathodic environments. For the treated SS316L under potentiostatic tests at $0.6 \mathrm{~V}$ for $0.5 \mathrm{~h}$, the corrosion current density is $1.84 \mu \mathrm{A} \cdot \mathrm{cm}^{-2}$, which is about one order of magnitude lower than the original SS316L.

2. When treated by the pickling and passivation method discussed in the present paper, the ICR of SS316L would be decreased from 286.7 to $11.3 \mathrm{~m} \Omega \cdot \mathrm{cm}^{2}$ at the compression pressure of $140 \mathrm{~N} \cdot \mathrm{cm}^{-2}$, which is approaching the 2020 DOE target of $10 \mathrm{~m} \Omega \cdot \mathrm{cm}^{2}$ at the same compression pressure.

3. The surface of SS316L becomes a little rougher but more uniform while more precipitates with higher conductivity generate after pickling and passivation. In the meanwhile, the ratio of $\mathrm{Cr}$ :Fe increases with lower oxygen content. They are the main reasons for the improvement of corrosion resistance and interfacial conductivity of SS316L by pickling and passivation.

4. The ICR of the treated SS316L increases to $29.5 \mathrm{~m} \Omega \cdot \mathrm{cm}^{2}$ while ICR of the original SS316L decreases to $38.6 \mathrm{~m} \Omega \cdot \mathrm{cm}^{2}$ at the compression pressure of $140 \mathrm{~N} \cdot \mathrm{cm}^{-2}$ after potentiodynamic tests. Intergranular corrosion and pitting are the main corrosion mechanism for both treated and original SS316L.

5. The results also indicate that the passive film formed by pickling and passivation may be unstable in the solution of $0.5 \mathrm{M} \mathrm{H}_{2} \mathrm{SO}_{4}$ and $2 \mathrm{ppm} \mathrm{HF}$, especially at the potentials higher than $0.9 \mathrm{~V}$ (vs. $\mathrm{Ag} / \mathrm{AgCl}$ ). Further efforts are needed to improve the performance and enhance the stability of the passive film in future research.

Author Contributions: Conceptualization, Y.L.; methodology, Y.L.; formal analysis, Y.L.; investigation, Y.L.; data curation, Y.L.; writing — original draft preparation, Y.L.; writing - review and editing, Y.L., C.Z., P.M., D.Y., B.L.; supervision, C.Z., P.M. and D.Y.; project administration, C.Z.; funding acquisition, P.M. All authors have read and agreed to the published version of the manuscript.

Funding: This research was funded by National Natural Science Foundation of China (Grant No. 2018YFB1502500).

Data Availability Statement: The data presented in this study are available on request from the corresponding author.

Acknowledgments: The authors would like to acknowledge the support of Fukang Gui (School of Automotive Studies, Tongji University) in pickling and passivation treatment of the specimens.

Conflicts of Interest: The authors declare no conflict of interest.

\section{References}

1. Leng, Y.; Ming, P.W.; Yang, D.J.; Zhang, C.M. Stainless steel bipolar plates for proton exchange membrane fuel cells: Materials, flow channel design and forming processes. J. Power Sources 2020, 451, 227783. [CrossRef]

2. Xu, Z.T.; Qiu, D.K.; Yi, P.Y.; Lai, X.M. Towards mass applications: A review on the challenges and developments in metallic bipolar plates for PEMFC. Prog. Nat. Sci. Mater. 2020, 30, 815-824. [CrossRef]

3. Karimi, S.; Fraser, N.; Roberts, B.; Foulkes, F.R. A review of metallic bipolar plates for proton exchange membrane fuel cells: Materials and fabrication methods. Adv. Mater. Sci. Eng. 2012, 2012, 1-22. [CrossRef]

4. Antunes, R.A.; Oliveira MC, L.; Ett, G.; Ett, V. Corrosion of metal bipolar plates for PEM fuel cells: A review. Int. J. Hydrog. Energy 2010, 35, 3632-3647. [CrossRef]

5. $\quad$ Borup, R.; Mukundan, R.; Lanl, T.R.; Brady, M.; Ornl, J.T.; Papadias, D.D. (Metal) Bipolar Plate Testing. In DOE 2017 Bipolar Plates Workshop; Los Alamos National Laboratory: Los Alamos, NM, USA, 2017.

6. Wilberforce, T.; Ijaodola, O.; Ogungbemi, E.; Khatib, F.N.; Leslie, T.; El-Hassan, Z.; Thomposon, J.; Olabi, A.G. Technical evaluation of proton exchange membrane (PEM) fuel cell performance-A review of the effects of bipolar plates coating. Renew. Sustain. Energy Rev. 2019, 113, 109286. [CrossRef]

7. Brady, M.; Wang, H.; Turner, J.; Meyer, H.; More, K.; Tortorelli, P.; McCarthy, B. Pre-oxidized and nitrided stainless steel alloy foil for proton exchange membrane fuel cell bipolar plates: Part 1. Corrosion, interfacial contact resistance, and surface structure. J. Power Sources 2010, 195, 5610-5618. [CrossRef]

8. Zhang, D.; Huang, K. Fe-Ni-Cr alloy as bipolar plate of PEMFC by multi-steps surface modification. Int. J. Hydrog. Energy 2015, 40, 13538-13548. [CrossRef] 
9. Kim, K.M.; Kim, J.H.; Kim, K.Y. Effect of Chemical Treatment on Interfacial Contact Resistance of Ferritic Stainless Steel as Bipolar Plate for PEMFC. ECS Trans. 2011, 41, 1861. [CrossRef]

10. Ishigami, O.; Kondo, T.; Ogawa, Y. Method for Passivating Stainless Steel Product and Method for Producing Stainless Steel Separator for Fuel Cell. U.S. Patent 7,785,425, 31 August 2010.

11. Jeon, Y.T.; Jeong, Y.S. Stainless Steel Separator for Fuel Cell and the Manufacturing Method Thereof. U.S. Patent 8,828,258, 9 September 2014.

12. Ishii, T.; Ishikawa, S.; Ujiro, T. Ferritic Stainless Steel Excellent in Corrosion Resistance and Conductivity and Method for Manufacturing the Same, Separator of Proton-Exchange Membrane Fuel Cell and Proton-Exchange Membrane Fuel Cell. U.S. Patent 9,587,297, 7 March 2017.

13. Kim, J.; Jo, K.; Kim, Y.; Lee, J.; Lee, Y.; Kim, J.; Seok, J.M. Stainless Steel for Polymer Fuel Cell Separator and Method for Preparing Same. U.S. Patent 9,290,845, 22 March 2016.

14. Yang, G.; Yu, S.; Mo, J.; Kang, Z.; Dohrmann, Y.; List, F.A., III; Green, J.B., Jr.; Babu, S.S.; Zhang, F.Y. Bipolar plate development with additive manufacturing and protective coating for durable and high-efficiency hydrogen production. J. Power Sources 2018, 396, 590-598. [CrossRef]

15. Rajasekar, S.; Chetty, R.; Neelakantan, L. Low-nickel austenitic stainless steel as an alternative to 316L bipolar plate for proton exchange membrane fuel cells. Int. J. Hydrog. Energy 2015, 40, 12413-12423. [CrossRef]

16. Abdallah, M. Corrosion behaviour of 304 stainless steel in sulphuric acid solutions and its inhibition by some substituted pyrazolones. Mater. Chem. Phys. 2003, 82, 786-792. [CrossRef] 